\title{
Interrenal steroid 21-hydroxylase in eels: primary structure, progesterone-specific activity and enhanced expression by ACTH
}

\author{
Y-Y Li, K Inoue and Y Takei \\ Laboratory of Physiology, Department of Marine Bioscience, Ocean Research Institute, University of Tokyo, 1-15-1 Minamidai, Nakano, \\ Tokyo 164-8639, Japan \\ (Requests for offprints should be addressed to Y Takei; Email: takei@ori.u-tokyo.ac.jp)
}

\begin{abstract}
Cytochrome P450 21-hydroxylase (P450c21) is a key enzyme for corticosteroidogenesis. To understand the regulatory mechanisms of cortisol production in fish, we have cloned a cDNA encoding P450c21, for the first time in non-mammalian vertebrates, from the head kidney of the eel (Anguilla japonica). The overall similarity of the deduced P450c21 sequence was modest (41-44\% amino acid identity) between the eel and mammals. However, the functional domains for steroid-binding, heme-binding and proton-transfer sites were well conserved (74-100\% identity). The eel P450c21 mRNA was expressed abundantly in the anterior quarter of the head kidney, but was undetectable in the remaining three-quarters or in other tissues including the gill, heart, liver, intestine, kidney, immature gonad and skeletal muscle. Functional expression of the cDNA clone in non-steroidogenic COS-1 cells produced a protein with high 21-hydroxylase activity to convert progesterone to 11-deoxycortisterone but not $17 \alpha$-hydroxyprogesterone to 11-deoxycortisol, although the latter is a preferred substrate for mammalian P450c21. To examine whether 21-hydroxylated progesterone is actually $17 \alpha$-hydroxylated in the eel interrenal, 11-deoxycorticosterone and ${ }^{3} \mathrm{H}$-corticosterone were respectively incubated with the interrenal-containing anterior quarter of the head kidney. The separation of the steroids produced by two HPLC systems revealed that cortisol was produced from both substrates, showing the $17 \alpha$-hydroxylation of 11-deoxycorticosterone and corticosterone in the eel interrenal. ACTH infused at $3 \mathrm{pmol} / \mathrm{kg}$ per min for $5 \mathrm{~h}$ consistently increased plasma cortisol levels and interrenal P450c21 mRNA levels in seawater eels. These results showed that the interrenal-specific eel P450c21 cloned in this study is involved in cortisol production through conversion of progesterone to 11-deoxycorticosterone in the interrenal-containing anterior quarter of eel head kidney. Furthermore, ACTH stimulates cortisol production in part through enhanced P450c21 expression in the eel interrenal.
\end{abstract}

Journal of Molecular Endocrinology (2003) 31, 327-340

\section{Introduction}

For the biosynthesis of corticosteroids from cholesterol, several enzymes such as cytochrome P450 cholesterol side-chain cleavage (P450scc), 21-hydroxylase (P450c21), 17 $\alpha$-hydroxylase (P450c17), 11 $\beta$-hydroxylase $(\mathrm{P} 450 \mathrm{c} 11)$ and $3 \beta$ hydroxysteroid dehydrogenase (3 $\beta$-HSD) are necessary. Among these enzymes, $\mathrm{P} 450 \mathrm{c} 21$ appears especially important, because in mammals it directs the steroidogenic pathway toward the production of corticosteroids principally through conversion of 17a-hydroxyprogesterone to 11-deoxycortisol
(Crawford et al. 1992). However, this is the only enzyme that has not been identified at the molecular level in non-mammalian species. In mammals, corticosteroid production is regulated acutely by the translocation of cholesterol from the outer to the inner mitochondrial membrane through the action of steroidogenic acute regulatory protein (StAR) (Stocco 2001), and chronically by the upregulation of steroidogenic enzymes (Hanukoglu 1992, Omura \& Morohashi 1995).

In teleost fish, cortisol is a major corticosteroid secreted from the interrenal tissue. Cortisol acts not only as a glucocorticoid but also as a 
mineralocorticoid, and it plays a pivotal role in adaptation to both fresh water (FW) and seawater (SW) environments (for review see McCormick 2001). Thus, the euryhaline eel serves as a good model for examining cortisol actions in fish, especially in relation to osmotic adaptation. Several hormones have been implicated in cortisol secretion (Arnold-Reed \& Balment 1991, 1994, Li \& Takei 2003), but the mechanisms of these hormone actions are poorly understood in fish. To understand the mechanisms, therefore, it is necessary to identify all factors that are involved in cortisol biosynthesis. In the eel, adrenocorticotrophin $(\mathrm{ACTH})$, angiotensin II (ANG II), atrial natriuretic peptide (ANP) and C-type natriuretic peptide all stimulate cortisol production (Henderson et al. 1976, Li \& Takei 2003, Li et al. 2003). Transfer of eels from FW to SW increases plasma cortisol levels in addition to ANG II and ANP (Tierney et al. 1995, Kaiya \& Takei 1996, Li et al. 2003). With regard to the cortisol-producing enzymes, cDNAs encoding P450c11 (Jiang et al. 1996), P450c17 (Kazeto et al. 2000) and P450scc (Y Kazeto, S Adachi \& K Yamauchi, personal communication) have been cloned in eels. As mentioned above, however, the cDNA encoding P450c21, a key enzyme for cortisol biosynthesis, has not yet been cloned in this fish.

In this study, a cDNA encoding P450c21 was cloned from the head kidney of SW-adapted eels. The tissue distribution of its mRNA was examined by RT-PGR. The cDNA was expressed in COS-1 cells, and the enzymatic activity of the expressed protein was examined using ${ }^{3} \mathrm{H}$-progesterone and ${ }^{3} \mathrm{H}-17 \alpha$-hydroxyprogesterone conversion. Unexpectedly, only progesterone was converted to 11-deoxycorticosterone by the expressed protein. In mammals, 17alpha-hydroxyprogesterone is a preferred substrate of $\mathrm{P} 450 \mathrm{c} 21$ for cortisol production, and once progesterone is 21-hydroxylated, 11-deoxycorticosterone is scarcely 17alphahydroxylated any more (Hanukoglu 1992). We therefore examined the ability of eel interrenal tissues for conversion of 11-deoxycorticosterone to cortisol using an in vitro incubation system. We also confirmed the conversion of ${ }^{3} \mathrm{H}$-corticosterone to cortisol in the same system, since 11deoxycorticosterone is readily converted to corticosterone by P450c11 in the eel interrenal (Jiang et al. 1998). Finally, changes in P450c21 expression in the interrenal were examined together with changes in plasma cortisol concentration after ACTH infusion to assess whether the cloned $\mathrm{P} 450 \mathrm{c} 21$ is involved in cortisol production after the hormonal stimuli.

\section{Materials and methods}

\section{Animals and tissue collection}

Cultured immature eels, Anguilla japonica $(184 \cdot 8 \pm 12 \cdot 5 \mathrm{~g}, n=20)$, were purchased from a local dealer. The gonads were too immature to distinguish their sexes by simple visual examination. Eels were maintained under the natural photoperiod in FW or SW tanks for more than 1 or 2 weeks respectively before use. Water in the tank was continuously circulated, aerated and regulated at $18{ }^{\circ} \mathrm{C}$. After anaesthetization of eels with $0 \cdot 1 \%$ $(\mathrm{w} / \mathrm{v})$ tricaine methanesulfonate (Sigma, St Louis, MO, USA), tissues (see below) were surgically isolated, immediately frozen in liquid nitrogen and stored at $-80{ }^{\circ} \mathrm{C}$.

\section{Isolation of RNA}

Total RNA was extracted from various tissues using ISOGEN (Nippon Gene, Toyama, Japan). For cloning of P450c21 cDNA, poly $(\mathrm{A})^{+}$-RNA was subsequently isolated from the total RNA extracted from the head kidney of a SW-adapted eel using Oligotex-dT30 (Japan Synthetic Rubber, Tokyo, Japan). RNA was quantified by measuring absorbance at $260 \mathrm{~nm}$ in a spectrophotometer (DU, Beckman Coulter, Fullerton, CA, USA).

\section{cDNA cloning by RT-PCR and 5'- and 3'-rapid amplification of CDNA end (RACE)}

The double-strand cDNA pool was prepared from $0 \cdot 5 \mu \mathrm{g}$ poly $(\mathrm{A})^{+}$-RNA using the SMART cDNA library construction kit (Clontech, Palo Alto, CA, USA) according to the supplier's instructions. PGR was then performed to amplify a partial cDNA fragment using degenerate primers S1 (5'-ATHGGNGGNAGNGARAC- ${ }^{\prime}$ ) and Al (5'CKNGGNGCRGANGGRAA-3'), which were designed based on the highly conserved regions of P450c21 peptides of the cow (accession no. $\mathrm{P} 00191)$, the pig (P15540), the mouse (P03940) and the human (P08686). PGR reactions were started with an initial denaturation at $94{ }^{\circ} \mathrm{C}$ for $1 \mathrm{~min}$ 
followed by 30 cycles at $94{ }^{\circ} \mathrm{C}$ for $60 \mathrm{~s}, 44^{\circ} \mathrm{C}$ for $30 \mathrm{~s}$ and $72{ }^{\circ} \mathrm{C}$ for $45 \mathrm{~s}$, and with a final extension step at $72{ }^{\circ} \mathrm{C}$ for $7 \mathrm{~min}$, in a total volume of $50 \mu \mathrm{l}$ containing $50 \mathrm{pmol}$ of each primer, $40 \mathrm{nmol}$ dNTP, $1 \mu$ template and 1 unit Ex Taq DNA polymerase (Takara Shuzo, Kyoto, Japan). The PCR products were isolated using the Geneclean Kit (Obigene Inc, Carlsbad, CA, USA), subcloned into pT7 Blue vector (Novagen, Madison, WI, USA) and sequenced using a 310 DNA sequencer (PE Biosystems, Foster City, CA, USA).

Subsequently, RACE was performed using the PGR protocol as described above. The primers used were gene-specific primers (A2, 5'-GATT GGGGATAATAATGGTGTCGT- $3^{\prime}$ and S2, 5'-TGCACTGCTTGTCTGCTCTGAT-3') and their respective adaptor primers, 5' PCR primer and CDS III/3' primer (Clontech) (Fig. 1). The PGR products were isolated, subcloned and sequenced as above. Full-length P450c21 cDNA was constructed by aligning the three overlapping cDNA fragments, i.e. the original fragment amplified from primer pair S1-A1, together with the $5^{\prime}$ and $3^{\prime}$ RACE products. Finally, the full coding region was amplified to confirm the sequence and used for transient expression.

\section{Transient expression of P450c21 in COS-1 cells}

Since three possible start codons (ATG) were found at nucleotides 31-33, 43-45 and 247-249 of eel P450c21 cDNA (Fig. 1), two fragments with different lengths were amplified: the shorter one starting from $\mathrm{ATG}_{247-249}$ was amplified with primers S4 (5'-GGGAATTCAACATGTTGGA GCTGACACGGG-3') and A3 (5'-GGGGCGG CTCAAGTTAATGGTCGTG-3') and the longer one starting from $\mathrm{ATG}_{31-33}$ was amplified with primers S5 (5'-CGGAATTGGTGATGCAAGT CTGCATGACAT-3') and A3 (Fig. 1). PCR was performed using Advantage 2 DNA Polymerase Mix (Clontech) at $95^{\circ} \mathrm{C}$ for $1 \mathrm{~min}$ followed by 25 cycles at $95^{\circ} \mathrm{C}$ for $30 \mathrm{~s}, 68^{\circ} \mathrm{C}$ for $3 \mathrm{~min}$ and finally one cycle at $68^{\circ} \mathrm{C}$ for $3 \mathrm{~min}$. The amplified fragments were first subcloned into pT7 Blue and, after confirmation of the sequence, they were inserted at the $E c o \mathrm{R} \mathrm{I/Not} \mathrm{I} \mathrm{site} \mathrm{into} \mathrm{the}$ expression vector pEGFP-N1 (Clontech). The recombinant expression vectors containing the shorter and longer fragments of eel $\mathrm{P} 450 \mathrm{c} 21$ cDNA were named pe21S-N1 and pe21L-N1 respectively. The original pEGFP-N1 was used for control.

For functional expression of P450c21, COS-1 cells (kindly provided by Dr M K Park, University of Tokyo) were plated into three $60 \times 15 \mathrm{~mm}$ culture dishes at $6 \cdot 4 \times 10^{5}$ cells per dish in $5 \mathrm{ml}$ Dulbecco's modified Eagle's medium (DMEM; Invitrogen, Carlsbad, CA, USA) containing 10\% fetal bovine serum and $0.1 \mathrm{mM}$ non-essential amino acids. After incubation at $37^{\circ} \mathrm{C}$ for 16 $24 \mathrm{~h}$ (the cells were $80-90 \%$ confluent), the cells were transfected with $5 \mu \mathrm{g}$ plasmid DNA (pe21SN1, pe21L-N1 or pEGFP-N1) using LIPOFECTAMINE PLUS Reagent (Invitrogen) according to the supplier's instructions. After pre-culture of transfected cells for 36-40 h, the medium was exchanged with $5 \mathrm{ml}$ DMEM containing 21 pmol ${ }^{3} \mathrm{H}$-progesterone and ${ }^{3} \mathrm{H}-17 \alpha$-hydroxyprogesterone (Amersham International plc, Amersham, Bucks, UK). Medium $(1 \mathrm{ml})$ was taken at 5 and $10 \mathrm{~h}$ of incubation and the steroids were extracted with diethyl ether. After drying under $\mathrm{N}_{2}$, the residues were dissolved in $0.4 \mathrm{ml} 40 \%$ acetonitrile and $0.1 \mathrm{ml}$ was subjected to reverse-phase HPLG analysis (see section on HPLC conditions).

\section{Tissue distribution of P450c21 mRNA expression evaluated by RT-PCR}

P450c21 expression was examined in the head kidney, kidney, brain, heart, liver, skeletal muscle, immature gonad, intestine and gill from five FW eels and two SW eels. Since eel head kidney comprises approximately $23 \%$ of the total body length, the tissues were divided anterio-posteriorly into four parts; P1, P2, P3 and P4 (Fig. 4). Total RNA $(2 \mu \mathrm{g})$ was reverse transcribed in $20 \mu \mathrm{l}$ reaction mixture with Superscript First-Strand Synthesis System for RT-PCR (Invitrogen) according to the manufacturer's protocol. The products were diluted 1:5 with distilled water and kept at $-20{ }^{\circ} \mathrm{C}$ until use. A negative control was run for each sample without reverse transcriptase to confirm the absence of genomic DNA contamination. PCR was run at $94{ }^{\circ} \mathrm{C}$ for $30 \mathrm{~s}, 60^{\circ} \mathrm{C}$ for $30 \mathrm{~s}$ and $72{ }^{\circ} \mathrm{C}$ for $60 \mathrm{~s}$ for 26 cycles with $20 \mathrm{pmol}$ primers S6 (5'-TGTGGATTTGTCAGAGGA CTTC- $\left.{ }^{\prime}\right)$ and A4 (5'-CACAGGTCTAAGTCTA AGCACGT-3') (Fig. 1) and $5 \mu$ l diluted template. The expression of eel glyceraldehyde-3-phosphate dehydrogenase (GAPDH) was used as internal 
gctetttegagtgataacctattaat $\overline{g t g}$

30

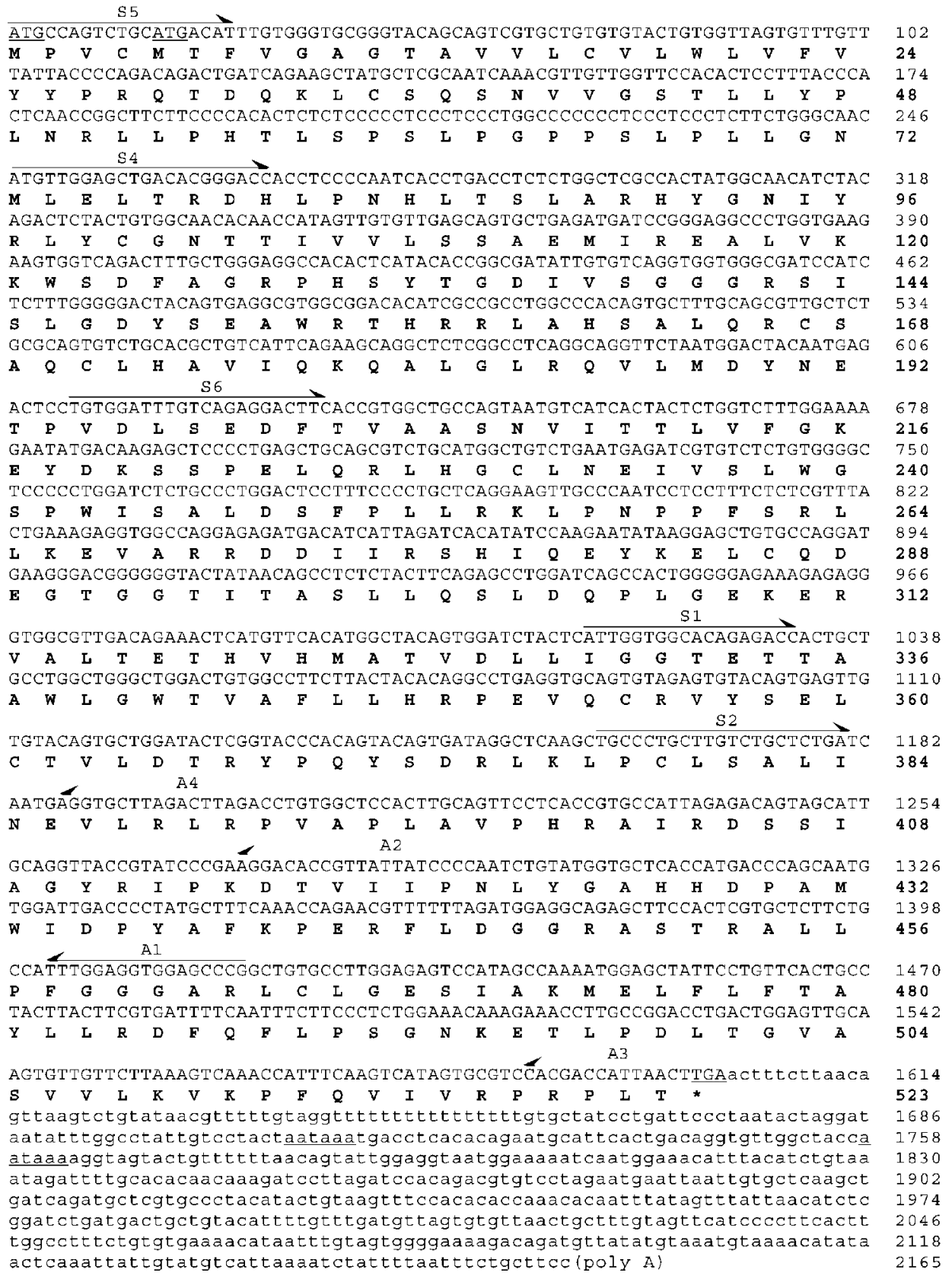

Figure 1 Nucleotide and predicted amino acid sequences of eel P450c21 cDNA. Nucleotide and amino acid numbers are shown on the right. Nucleotides in the untranslated region are in lower case. Two possible start codons (ATG), a termination codon (TGA) and two putative polyadenylation signals are underlined. Primer sequences used in this study are indicated by arrows (see Materials and methods).

controls as described previously (Takei et al. 2001). PCR was run for 24 cycles at $94{ }^{\circ} \mathrm{C}$ for $30 \mathrm{~s}, 62{ }^{\circ} \mathrm{C}$ for $30 \mathrm{~s}$ and $72{ }^{\circ} \mathrm{C}$ for $60 \mathrm{~s}$. The PGR condition was within the linear range of amplification for both genes in the interrenal tissue. The PCR products were electrophoresed in $1-1 \cdot 2 \%$ agarose gels 
containing ethidium bromide (EtBr), and observed in an FAS-III Electronic U.V. Transilluminator (Toyobo, Osaka, Japan).

\section{In vitro incubation of steroids with interrenal tissue}

\section{Conversion of 11-deoxycorticosterone to cortisol}

Since expressed eel P450c21 converted progesterone but not $17 \alpha$-hydroxycorticosterone, and since the interrenal tissue that expresses $\mathrm{P} 450 \mathrm{c} 21$ was exclusively localized in the anterior quarter (P1 segment) of the head kidney, we examined whether 11 -deoxycorticosterone is actually converted to cortisol after incubation with interrenal tissue. The head kidney was excised from two FW eels, cut anterio-posteriorly into four parts, and the $\mathrm{P} 1$ and $\mathrm{P} 4$ segments were used for experimental and control respectively. Each segment was minced with iris scissors, washed twice in sterile isotonic saline and incubated in $5 \mathrm{ml}$ sterile Hank's balanced salt solution (HBSS; Life Technologies, Grand Island, NY, USA) at $27{ }^{\circ} \mathrm{C}$ with gentle agitation. After 1-h preincubation, $5 \mu \mathrm{l} 25 \mathrm{mM} 11$-deoxycorticosterone (Sigma) in ethanol was added (final concentration, $25 \mu \mathrm{M})$, and the incubation continued for a further 1,3 and $7 \mathrm{~h}$ at $27{ }^{\circ} \mathrm{C}$. Neither ${ }^{3} \mathrm{H}$ - nor ${ }^{14} \mathrm{C}$ deoxycorticosterone were commercially available. At each time-point, $200 \mu \mathrm{l}$ medium was taken, spun at $14000 \mathrm{~g}$ for $5 \mathrm{~min}$, and the supernatant was directly applied to HPLC analysis (see section on HPLC conditions). After the termination of incubation, all minced tissues were collected, freezedried and weighed. The P1 and P4 segments weighed $8 \cdot 30$ and $7 \cdot 84 \mathrm{mg}$ respectively.

\section{Conversion of ${ }^{3} \mathrm{H}$-corticosterone to cortisol}

Since eel P450c11 cloned from eel interrenal readily converts 11-deoxycorticosterone to corticosterone (Jiang et al. 1998), we examined whether eel interrenal can convert corticosterone to cortisol. The $\mathrm{P} 1$ and $\mathrm{P} 4$ segments from two different FW eels were incubated in $2.5 \mathrm{ml} \mathrm{HBSS}$ as above, and $7.5 \mu \mathrm{l}{ }^{3} \mathrm{H}$-corticosterone (Perkin Elmer Life Sciences, Boston, MA, USA) was added to the medium at a final concentration of $30 \mathrm{nM}$. After 1 , 3,7 and $21 \mathrm{~h}$ of incubation, $100 \mu \mathrm{l}$ medium was taken and spun at $14000 \mathrm{~g}$. The supernatant was applied to the HPLG analysis. The elution condition and detection of radioactivity were the same as for functional expression (see section on HPLC conditions).

\section{HPLC conditions}

In the sections 'Transient expression of $\mathrm{P} 450 \mathrm{c} 21$ in COS- 1 cells' and 'Conversion of ${ }^{3} \mathrm{H}$-corticosterone to cortisol', steroids were separated in the reverse-phase column (ODS-120T, 4.6 × $250 \mathrm{~mm}$; Tosoh, Tokyo, Japan) with a linear gradient of acetonitrile concentration from 40 to $70 \%$ over $30 \mathrm{~min}$ at $0.7 \mathrm{ml} / \mathrm{min}$. The radioactivity of the eluate was monitored in a radiomatic flow scintillation analyzer (500TR; Perkin Elmer Inc., Shelton, GT, USA). The elution positions of progesterone, 17 $\alpha$-hydroxyprogesterone, 11deoxycorticosterone, 11-deoxycortisol, corticosterone and cortisol were determined at $274 \mathrm{~nm}$ by authentic steroids (Sigma-Aldrich, St Louis, MO, USA). Since 11-deoxycortisol and corticosterone were indistinguishable by this elution condition, a different system was applied to the experiment in the section on 'Conversion of 11deoxycorticosterone to cortisol'. In this experiment, the column was eluted with a linear gradient of methanol/acetonitrile concentration in water from 20 to $40 \%$ in $30 \mathrm{~min}$ at $0.7 \mathrm{ml} / \mathrm{min}$, which was modified from Nunez \& Trant (1999). The steroid peaks were detected at $240 \mathrm{~nm}$ to minimize the absorption of contaminated proteins. Under this condition, corticosterone and 11-deoxycortisol are apparently distinguishable.

\section{Effects of ACTH on plasma cortisol and P450c21 mRNA}

\section{ACTH infusion}

Six FW eels were used in this experiment. After anaesthesia in $0 \cdot 1 \%$ tricaine methanesulfonate, polyethylene tubes (SP 10, outside diameter $=0.61 \mathrm{~mm}$; Natsume, Tokyo, Japan) were surgically inserted into the ventral aorta for blood sampling and into the dorsal aorta for infusion. After operation, eels were transferred to individual plastic troughs through which aerated and filtered SW was continuously circulated at $18{ }^{\circ} \mathrm{C}$. The troughs were covered with a black vinyl sheet to minimize visual stress during experiments. On the day after surgery, ACTH (human, 1-24; Peptide Institute Inc., Osaka, Japan) dissolved in $0.9 \% \mathrm{NaCl}$ solution was infused into the eel at $3 \mathrm{pmol} / \mathrm{kg}$ per $\mathrm{min}$ in a volume of $8 \cdot 3 \mu \mathrm{l} / \mathrm{min}$. 
Eel 1

Bovine

Pig

MPVCMTFVGAGTAVVLCVLWLVFVYYPRQTDQKLCSQSNVVGSTLLYPLNRLLPHTLSPS 60

Human

MVLAGL - LLLTLLA - AH - - WGRWK - RNLH - P - L 33

Mouse

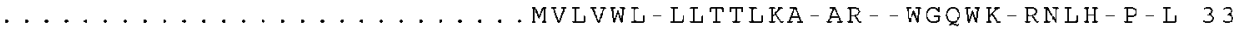

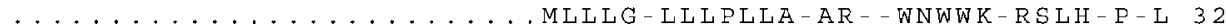

Eel LPGPSLPLLGNLELTRDHLNHLTSLARHGNIYRLYCGNTTIVVLSSAEMIREALV I20

Bovine V- .......F-H-LQPN--I- - L- TQKL-PV- - RL-LQEV- - N-KRT-E- -MIR 84

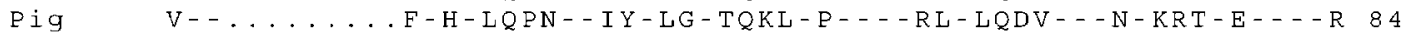

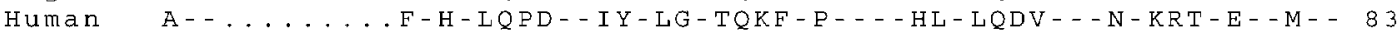

Mouse $\quad A-\ldots \ldots \ldots . F-H F L Q P N--I Y-L G-T Q K L-P---I R L-M Q D V---N-N R T-E--I Q 84$

Ee1 KWSDFAGRHSYTGDIVSGGGRSISLGDYSEAWRTHRRLAHSALQRCSAQCLHAVIQKQA 180

Bovine - - V- - - - QIPSYKL- - QRCQD- - - - - LL-KA-KK-TR - - LLGTRSSMEPWVDQLT 144

Pig - - V- - - - QIPSYKLA-QHCPD- - - - - LF-KA-KK-TR - - LLGVRSSMEPRVCQLT 144

Human - A - - - EPL-YKL - KNYPDL - . - - LL - KA - KR - TR - - LLGIRDSMEP-VEQLT 143

Mouse $\quad-\mathrm{V} \ldots \ldots$.....HMLNGKMDLDL $\ldots . .-$ LM-KA-KR-SR - - MLGMRDSMEPL-EQLT 140

Ee1 LGLRQVLMDYNETPVDLSEDFTVAASNVITTLVFGKEYDKSSPELQRLHGCLNEIVSLWG 240

BOVine QEFCERMRVQAGA--TIQKE-SLLTCSI-CY-T--NKE. . DTLVHAF-D-VQDLMKT-D 201

Pig QEFCERMRAQAG- - TIQKE-S-LTCSI-CC-T--DKE. . DTLVHA-D-VQDLMKT-D 201

Human QEFCERMRAQPG- - AIE-E-SLLTCSI-CY-T--DKIKD.DNLMPAYYK-IQ-VLKT-S 202

Mouse QEFCERMRAQAG-- - AIHKE-SFLTCSI-SC-T--DND . . -TLV-T--D-VQDLLQA-N 197

EEI SPWISALDSFLLRKLFNPPFSRLKEVARRDDIRSHIQEYKELCQDEGTGGTITASLL 300

BOVine HWS-QI--MV-F--FF---GLW--KQAIEN--HMVEKQLTRH--S.MVA-QWRDM-DYM-260

Pig HWS-QI--MV-F- - FF-S-GLR- - KQAIEN- - HLVEKQLRRH - S.MVA-QWRDMLDYM- 260

Human HWS-QIV-VI-F-FF-- GLR--KQAIEK--H-VEMQLRQH- S. LVA-QWRDMMDYM-26I

Mouse HWS-QI-TII-_-F-_-GLQK-KQIQES--H-VKQQLKQH--S. LVA-QWKDMIDYM- 257

Eel QSLDQPLGEKERVALTETHVHMATVDLLIGGTETTAAWLGWTVAFLLHREVQCRVYSEL 360

Bovine -GVGRQRV-EGPGQ-L-G- - - SV- - F- - - - - ST - S - A - - - - - - - I-R- LQE- - 320

Pig - EAGRQRV-EGQGQ-L-G- - - SV- - F- - - - - NT-S-A-VY- - - H - - I-W-LQE- - 320

Human -GVA--SM-EGSGQ-L-G- - - A- - - - - - - NT-S-A-V-- - H- - I-Q-LQE- 321

Mouse -GVEKQRDG-DEER-H-G- - - SV- - F- - - _- - TT-S-A - - - - H - - I-K-LQA- - 317

steroid-hinding site

Eel CTVLDTR. . . YPQYSDRLKLPCLSALINEVLRLRPVAPLAVPHRAIRDSSIAGYRIPKD 416

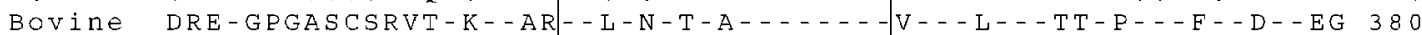

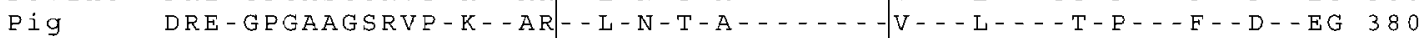

Human DHE-GEGASSSRVP-K- - AR - - L - N-T-A- - - - V - - L - - TT-P- - S- D - EG 381

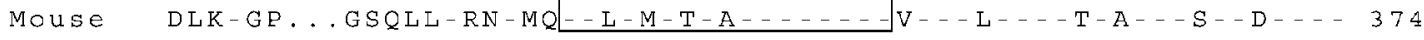

Eel TVIIPNLYGAHHDPAMWIDPYAFRERFLDGGRASTRALLPFGGGARLCLGESIAKMELF 476

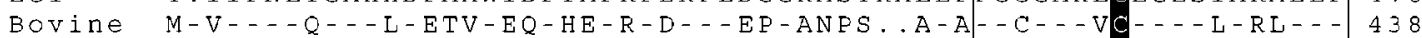

Pig - - V- - - Q- - IL-ETV-EQ-HE-R-D- - AP-ANES. A - A - - C- - - VC- - PL-RL- - 438

Human - - - - Q - - L-ETV-ER-HE-W-D- - EP-KN-R. . A - A - - C- - VC- - PI-RL- - 439

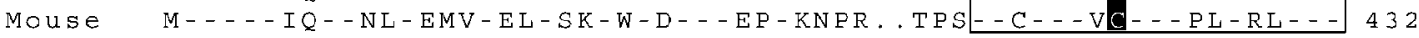

Eel LFTAYLLRDFQFLPGNKETLPDLTG . VVASVVLKVKRFQVIVRPRPLT. . . . . 523

Bovine VVLLR--QA-TL--PP.VGA--S-QPDPYCG-N---Q---RLQ--GVEAGAWESASAQ 496

Pig VVLVQ- - QA-TL- - P..EGA- - S-QPVPYSGIN- - Q- - - RLQ- - GGRGEGPGPR. . 492

Human VVLTR--QA-TL-...GDA- - S-QPLPHC- - I-MQ- - - RLQ- -GMGAHSPGQNQ. 494

Mouse VVL-R--QA-TL--PP.DG-- - S-QPQPY-GIN-FIP- - -RLQ--N-APQDQGERP.. 487

Figure 2 Comparison of amino acid sequences of eel P450c21 with those of mammals. Sequences were aligned by Clustal W in DDBJ website at http://www.ddbj.nig.ac.jp. The accession numbers were: bovine (P00191), pig (P15540), human (P08686) and mouse (P03940). Amino acid numbers are shown on the right. Dashes represent identical amino acid residues and dots represent gaps. Putative proton-transfer, steroid-binding and heme-binding sites are boxed. The cysteine residue in the heme-binding sites which, it is suggested, co-ordinates with the heme-prosthetic group, is highlighted by a black box.

Infusion of vehicle alone served as control. Human ACTH is only one amino acid different in its structure from eel ACTH (accession no. AF194969) (Dewied 1990) and exhibits full steroidogenic activity in fish (Young 1993). Blood (approximately $30 \mu \mathrm{l}$ ) was collected into a capillary before and every hour after the start of infusion. The blood volume removed was replaced immediately by a vehicle injection. 
After centrifugation, plasma was stored at $-20^{\circ} \mathrm{C}$ for subsequent cortisol determination. Five hours after infusion, eels were anaesthetized and the anterior part (P1 segment) of the head kidney was collected from each eel for RNA extraction. All fish were killed at the same time of the day.

\section{Comparison of P450c21 mRNA expression}

The P450c21 mRNA in the P1 segment of head kidney was compared between ACTH- and saline-infused eels by RT-PCR as described previously (Li et al. 2003). The RT-PGR protocol was the same as that used for examining tissue distribution. PGR cycles were 26 for P450c21 and 24 for GAPDH (internal control). We confirmed in the pilot experiments using serially diluted templates that the signal intensity of PCR products and the amount of template exhibited linear relationship under the current PGR conditions (data not shown). Each PCR product $(10 \mu \mathrm{l})$ was electrophoresed in $1.2 \%$ agarose gels, stained with $\mathrm{EtBr}$ and quantitated using an imaging analyzer (FLA-2000; Fuji Film, Tokyo, Japan).

\section{Cortisol measurement}

Plasma cortisol was measured by enzyme immunoassay after extraction with ethyl ether as described previously (Li \& Takei 2003). Crossreactivity of the anti-cortisol serum used in the assay was $31 \%$ with 11-deoxycortisol, $6 \cdot 0 \%$ with cortisone, $3 \cdot 6 \%$ with corticosterone, $0 \cdot 1 \%$ with progesterone and $<0 \cdot 1 \%$ with oestradiol. Measurements were carried out in duplicate.

\section{Statistics}

All data are presented as means \pm S.E.M. Paired $t$-test was used to determine statistical differences of plasma cortisol concentrations before and after ACTH or saline infusion in the same fish. Student's $t$-test was applied for comparison of plasma cortisol and P450c21 mRNA levels between ACTH- and saline-infused eels. Significance was set at $P<0 \cdot 05$.

\section{Results}

\section{Nucleotide and amino acid sequences of eel P450c21 cDNA}

Using a combination of RT-PCR and RACE, a P450c21 cDNA (accession no. AB095111) of 2165 bp length (excluding the poly (A) tail) was isolated from the eel head kidney (Fig. 1). The open reading frame $(\mathrm{ORF})$ started from nucleotide 31 and encoded 523 amino acids. Methionine codons were also located at nucleotides 43-45 and 247-249 (Fig. 1). The 3'-untranslated region had $563 \mathrm{bp}$, where two possible AATAAA polyadenylation signals were found. The predicted eel P450c21 protein displayed 41-44\% overall identity with those of mammals, and contained all functional domains for steroid binding, heme binding and proton transfer in which the similarities were $77 \%, 74 \%$ and $100 \%$ respectively (Fig. 2).

\section{1-Hydroxylation activity of eel P450c21 expressed in COS-1 cells}

The COS-1 cells transfected with pe21L-N1, containing the whole ORF (starting from $\mathrm{ATG}_{31-33}$ ) of eel P450c21 cDNA, converted most progesterone to 11-deoxycorticosterone in $5 \mathrm{~h}$ (Fig. 3). However, no obvious conversion of $17 \alpha$-hydroxyprogesterone was observed even after $10 \mathrm{~h}$. The COS-1 cells transfected with pe21S$\mathrm{Nl}$, containing the partial ORF (starting from $\left.\mathrm{ATG}_{247-249}\right)$, converted neither progesterone nor $17 \alpha$-hydroxyprogesterone (data not shown), as observed in controls transfected only with the vector (Fig. 3).

\section{Tissue distribution of eel P450c21 mRNA}

P450c21 mRNA displayed consistent tissue-specific expression in all FW and SW eels. Abundant P450c21 mRNA was detected only in the head kidney (Fig. 4). More detailed analyses of the head kidney located the expression only in the anterior quarter $(\mathrm{P} 1)$. The negative tissues included the kidney, brain, heart, intestine, liver, gill, immature gonad and skeletal muscle (Fig. 4).

\section{Conversion of 11-deoxycorticosterone to cortisol in eel interrenal}

Incubation of 11-deoxycorticosterone with the P1 segment of head kidney containing interrenal tissue produced cortisol and its intermediate products, 11-deoxycortisol and corticosterone, depending on the incubation time (Fig. 5). However, incubation with the P4 segment scarcely converted 11deoxycorticosterone to any other steroid including cortisol (Fig. 5). Thus the P1 segment contained both $\mathrm{P} 450 \mathrm{c} 17$ and P450c11. 


\section{Control}

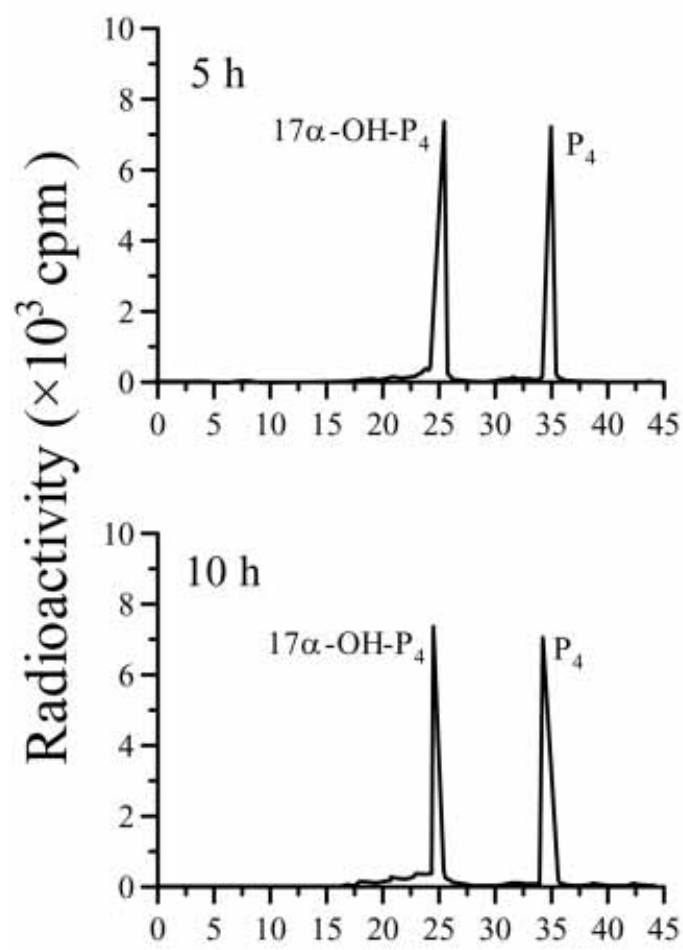

\section{Experimental}
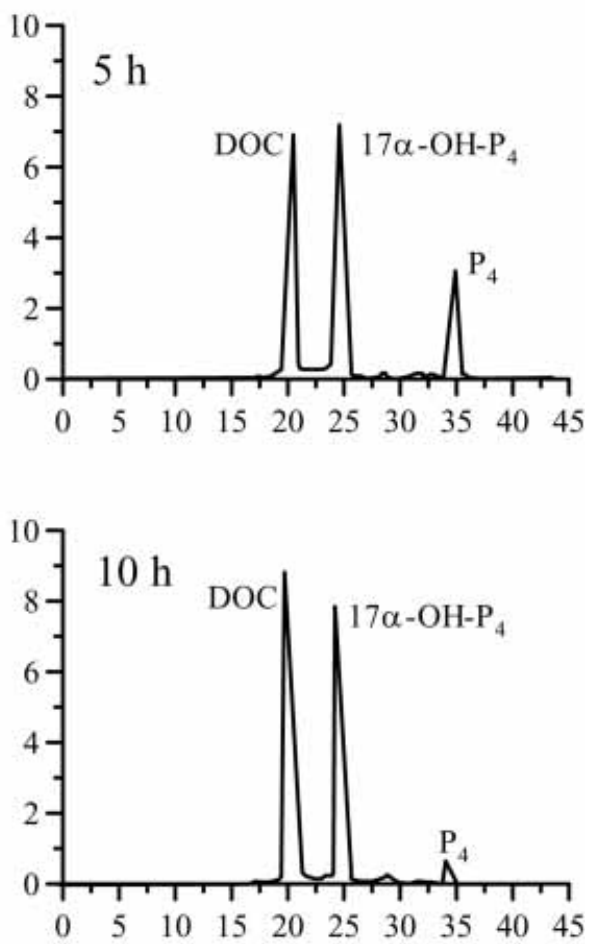

\section{Retention time ( $\mathrm{min})$}

Figure 3 Radiochromatograms showing specific conversion of ${ }^{3} \mathrm{H}$-progesterone $\left(\mathrm{P}_{4}\right)$ to 11-deoxycorticosterone (DOC). ${ }^{3} \mathrm{H}-\mathrm{P}_{4}$ and ${ }^{3} \mathrm{H}-17 \alpha$-hydroxyprogesterone $\left({ }^{3} \mathrm{H}-17 \alpha-\mathrm{OH}-\mathrm{P}_{4}\right)$ were incubated together with COS-1 cells transfected with vector only (control) or vector containing the whole ORF of eel P450c21 cDNA (experimental). Incubation medium was collected after 5 and $10 \mathrm{~h}$. The steroids produced were separated by reverse-phase HPLC using an ODS-120T column $(4.6 \times 250 \mathrm{~mm})$ with a linear gradient of acetonitrile concentrations from 40 to $70 \%$ in $30 \mathrm{~min}$ at $0.7 \mathrm{ml} / \mathrm{min}$, and radioactive peaks were detected in a radiomatic flow scintillation analyzer.

Incubation of ${ }^{3} \mathrm{H}$-corticosterone with the $\mathrm{Pl}$ segment time-dependently produced cortisol (Fig. $6)$, showing that interrenal P450c17 can act on corticosterone. After $21 \mathrm{~h}$ of incubation, the major product was cortisol among others (Fig. 7). However, incubation with the P4 segment failed to produce any cortisol (Fig. 6), and a significant amount of corticosterone still remained after $21 \mathrm{~h}$ of incubation (Fig. 7).

\section{Effects of ACTH on plasma cortisol and P450c21 mRNA levels in head kidney}

A sustained increase in plasma cortisol concentration was observed in eels infused with ACTH at
$3 \mathrm{pmol} / \mathrm{kg}$ per min for $5 \mathrm{~h}$ compared with the preinfused level or with the level of saline-infused controls (Fig. 8). The expression of P450c21 mRNA in the P1 segment of head kidney also increased after $5 \mathrm{~h}$ of ACTH infusion.

\section{Discussion}

\section{Structural characteristics of eel P450c21}

To date, the cDNAs encoding P450c21 have been cloned in various mammalian species (e.g. Yoshioka et al. 1986, Crawford et al. 1992, Zhou et al. 1997). In fish, the presence of P450c21 activity in the interrenals of teleosts has been suggested (Sampath-Kumar et al. 1996, Blom et al. 2001), as 


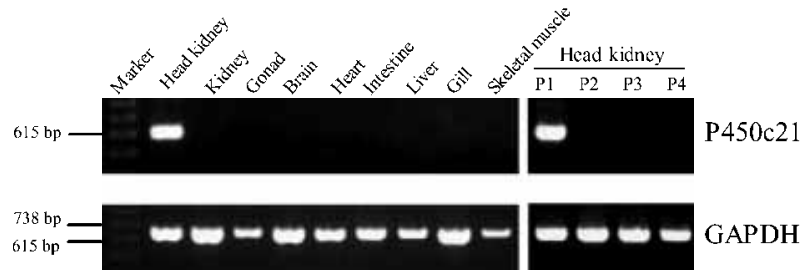

Figure 4 Tissue distribution of P450c21 mRNA examined by RT-PCR. The expression of eel GAPDH was used as internal control. Specific expression in the P1 segment of head kidney occurred in all samples from five FW and two SW eels. The head kidney was divided equally into four parts, and named P1-P4 from the anterior to the posterior direction.

well as in elasmobranchs (Nunez \& Trant 1995). However, a P450c21 cDNA has not yet been cloned in any non-mammalian vertebrate, including fish.

In this study, a P450c21 cDNA was cloned from the eel head kidney. At the $5^{\prime}$ region of its cDNA, possible start codons (ATG) were found at three positions. The studies of functional expression showed that the 21-hydroxylase activity was detected only with the cDNA that contains the longest ORF starting from $\mathrm{ATG}_{31-33}$, and not with that starting from $\mathrm{ATG}_{247-249}$. This result showed that the first or second ATG are used as the start codon, and that the N-terminal region of eel P450c21 is essential for its activity as demonstrated for human P450c21 (Hsu et al. 1993). The similarity of $\mathrm{P} 450 \mathrm{c} 21$ protein between eels and mammals was low $(41-44 \%)$. Nevertheless, the putative functional domains for steroid binding, heme binding and proton transfer, as identified in mammalian P450c21s (John et al. 1986, Crawford et al. 1992, White \& Speiser 2000), displayed high identity (74-100\%) between eels and mammals, suggesting their importance for enzyme activity.

\section{Tissue-specific expression of eel P450c21}

The interrenal steroidogenic tissue in fish is homologous to mammalian adrenal cortex, and is the site for corticosteroid biosynthesis (Chung et al. 1986, Nunez \& Trant 1995, White \& Speiser 2000). In the eel, the interrenal cells are closely associated with blood vessels of the head kidney (Sandor et al. 1966, Takashima \& Hibiya 1995). The head kidney of the eel is a long tissue that extends from the kidney to the heart and spans more than $20 \%$ of the total body length. Since the head kidney is essentially a haematopoietic tissue in fish, we chose to determine which part of the head kidney contains interrenal cells. In the present study, P450c21 mRNA was expressed exclusively in the anterior quarter $(\mathrm{Pl})$ of the head kidney, suggesting that the interrenal steroidogenic cells are represented only in this part. The expression of P450c21 mRNA has also been detected exclusively in the adrenal cortex in mammals (John et al. 1986, Zhou et al. 1997). On the other hand, other eel proteins related to corticosteroidogenesis such as $\mathrm{P} 450 \mathrm{c} 17$ and P450c11 and StAR are expressed in the gonads and/or interrenal (Jiang et al. 1998, Kazeto et al. 2000, Li et al. 2003).

\section{Enzymatic activity of eel P450c21 expressed in cos- 1 cells}

In mammals, P450c21 expressed in COS cells converts both progesterone and $17 \alpha$ hydroxyprogesterone to their 21-hydroxylated products (Lorence et al. 1989, Crawford et al. 1992, Zhou et al. 1997). In the in vitro incubation of bovine adrenocortical homogenates, however, the presence of two 21-hydroxylases have been suggested, one for a 17-deoxy substrate (e.g. progesterone) and the other for a 17-hydroxylated one (e.g. 17 $\alpha$ hydroxyprogesterone) (Kahnt \& Neher 1972). Since P450c21 cDNA has not yet been cloned in non-mammalian species, their substrate specificity is not known. However, indirect evidence from in vitro studies has indicated that in elasmobranchs, amphibians, reptiles and birds, progesterone is the major substrate of $\mathrm{P} 450 \mathrm{c} 21$ because of the absence of $\mathrm{P} 450 \mathrm{cl} 7$ in the adrenal/interrenal of these groups (Lofts \& Bern 1972, Nunez \& Trant 1995). In teleosts, limited studies suggest that both progesterone and 17 $\alpha$-hydroxyprogesterone may be 21-hydroxylated in the interrenal (Sandor et al. 1966, Idler \& Truscott 1972). However, the preferential substrate of $\mathrm{P} 450 \mathrm{c} 21$ might differ with species, developmental stage and season (Lofts \& Bern 1972, Sangalang \& Uthe 1994).

In this study, cloned P450c21 actively converted progesterone to 11-deoxycorticosterone, displaying the characteristic enzyme activity. However, the cloned enzyme did not convert $17 \alpha$-hydroxyprogesterone, i.e. it lacked $17 \alpha$ hydroxyprogesterone 21-hydroxylase activity. It is possible that COS cells lack specific factor(s) 


\section{Control}
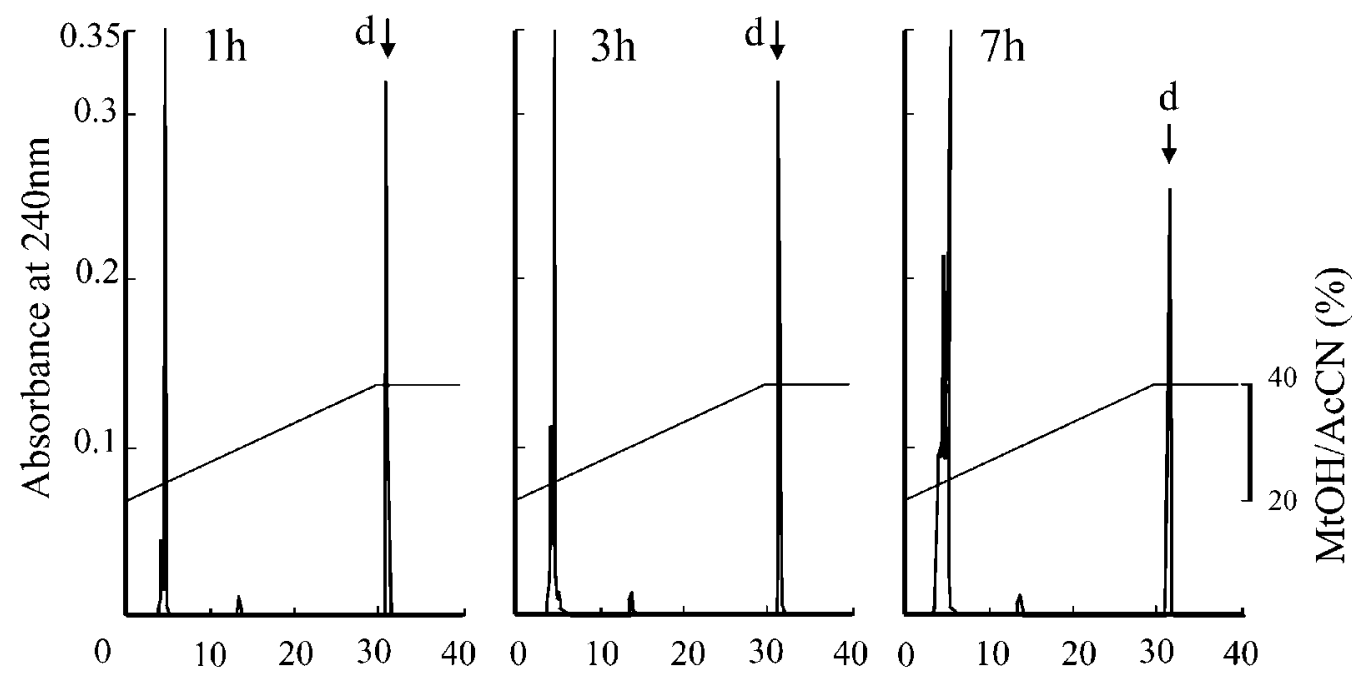

\section{Experimental}
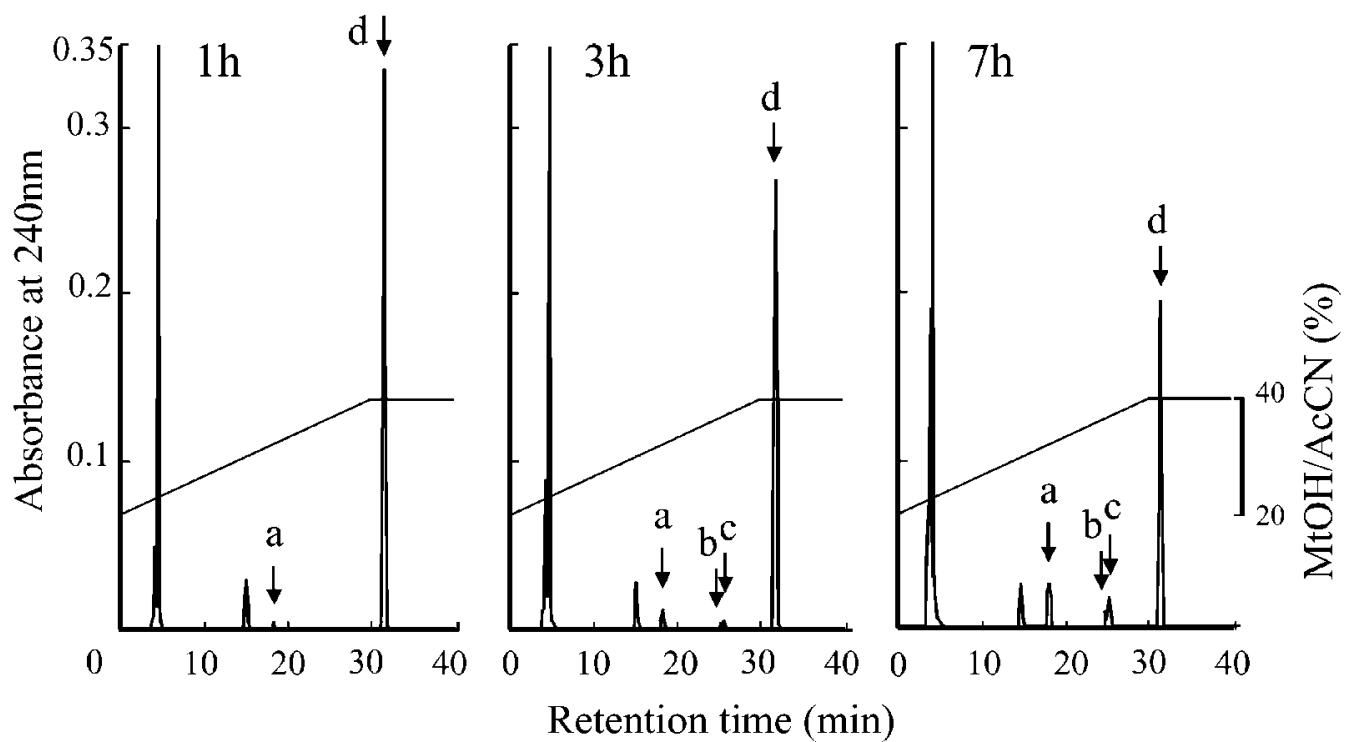

Figure 5 Time-course of conversion of 11-deoxycorticosterone after incubation with eel head kidney. The steroid was incubated either with the anterior P1 segment of head kidney (experimental) or the posterior P4 segment (control). While 11-deoxycorticosterone (d) was hardly converted in the control group, it was time-dependently converted to produce cortisol (a), 11-deoxycortisol (b) and corticosterone (c) in the experimental group. Other peaks without arrows did not change with time. The steroids produced were separated by reverse-phase HPLC using an ODS-120T column $(4.6 \times 250 \mathrm{~mm})$ with a linear gradient of methanol $(\mathrm{MtOH}) /$ acetonitrile $(\mathrm{AcCN})$ concentrations from 20 to $40 \%$ in $30 \mathrm{~min}$ at $0.7 \mathrm{ml} / \mathrm{min}$.

needed for this activity. In a previous study, however, ovine P450c21 expressed in COS cells catalysed both progesterone and
17 $\alpha$-hydroxyprogesterone (Crawford et al. 1992). Thus, the progesterone-specific activity seems to be intrinsic to the enzyme found in this study. 


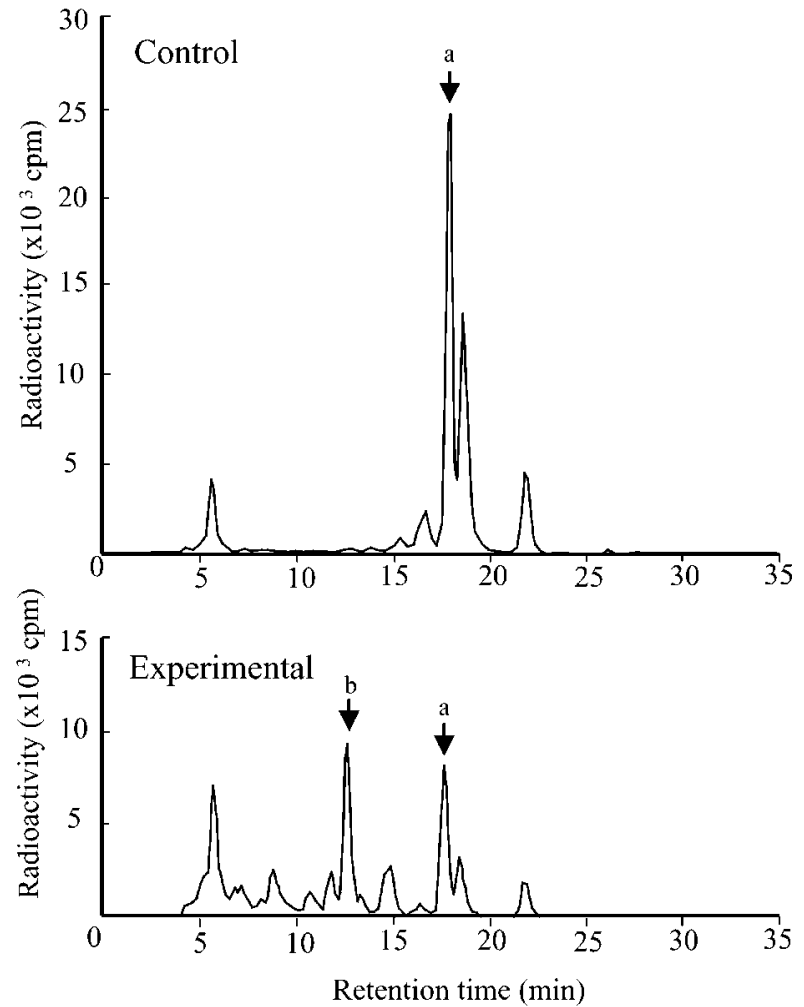

Figure 6 HPLC profiles showing conversion of ${ }^{3} \mathrm{H}$-corticosterone (a) to ${ }^{3} \mathrm{H}$-cortisol (b) after $21 \mathrm{~h}$ of incubation with eel head kidney. After incubation, radioactive steroids were separated by reverse-phase HPLC in the same conditions as in Fig. 3 . While corticosterone still remained in considerable amounts after incubation with the P4 segment (control), cortisol was a major product after incubation with the P1 segment (experimental). Most radioactive peaks of unknown products occurred in both control and experimental groups.

In vitro tissue incubation experiments have shown that progesterone is converted to 11deoxycorticostrone in the interrenal of the European eel (Sandor et al. 1966). Therefore, an enzyme activity similar to that of the cloned P450c21 also appears to be present in the interrenal of this species of eel.

\section{Biosynthetic pathway of cortisol in eel interrenal}

Since the interrenal-specific P450c21 cloned in this study specifically converted progesterone to 11deoxycorticosterone, the latter should be converted to cortisol in the interrenal. In fact, 11deoxycorticosterone incubated with eel interrenal

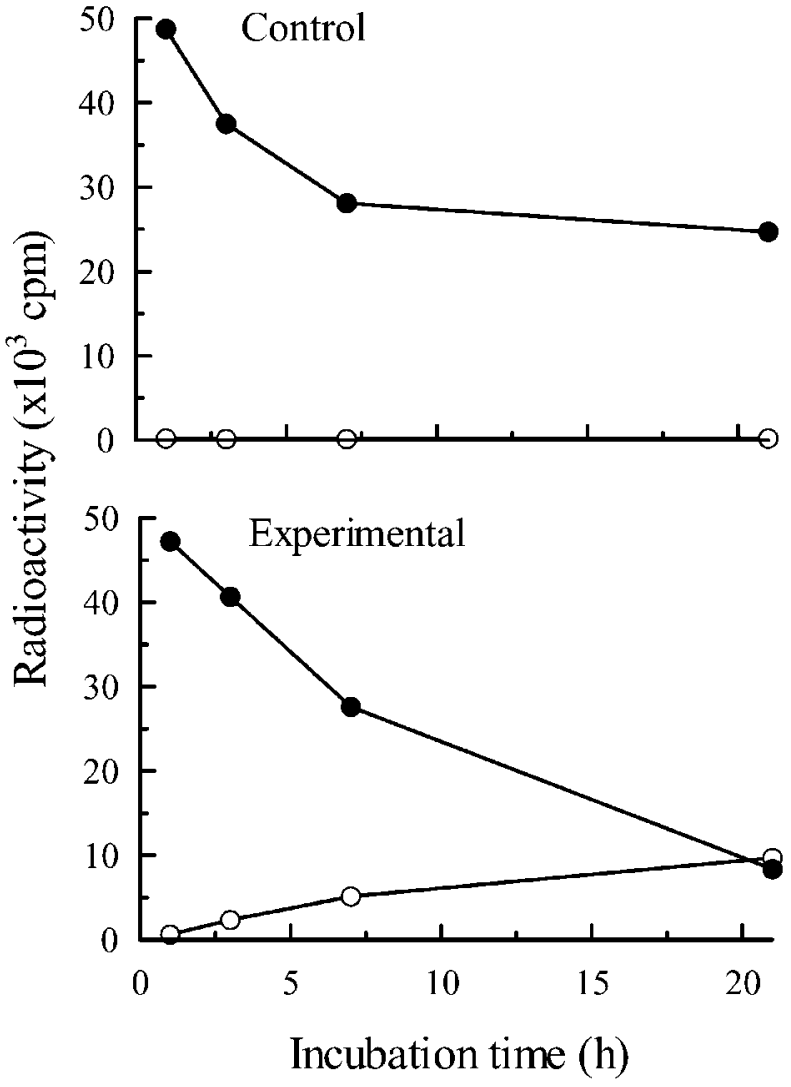

Figure 7 Time-course of conversion of ${ }^{3} \mathrm{H}$-corticosterone $(\bullet)$ to ${ }^{3} \mathrm{H}$-cortisol (०) after incubation with eel head kidney. Cortisol was not produced after $21 \mathrm{~h}$ of incubation with the P4 segment of head kidney (control), but it was time-dependently produced after incubation with the P1 segment (experimental).

was converted to cortisol in this study. Both corticosterone and 11-deoxycortisol were detected after incubation. Thus both pathways through these intermediate products are active in the eel interrenal. Jiang et al. (1998) showed that the P450c1l enzyme that is abundantly expressed in the interrenal of Japanese eel converts both 11-deoxycorticosterone and 11-deoxycortisol to corticosterone and cortisol respectively. Judging from their data, however, 11-deoxycorticosterone appears to be a preferential substrate. Actually, the eel interrenal tissue actively converted ${ }^{3} \mathrm{H}$ corticosterone to cortisol in this study. 17 $\alpha$ Hydroxylation of corticosterone to produce cortisol has previously been reported in fish including the European eel (Sandor et al. 1966). Together with the present data, it seems that the route for cortisol biosynthesis from progesterone through 

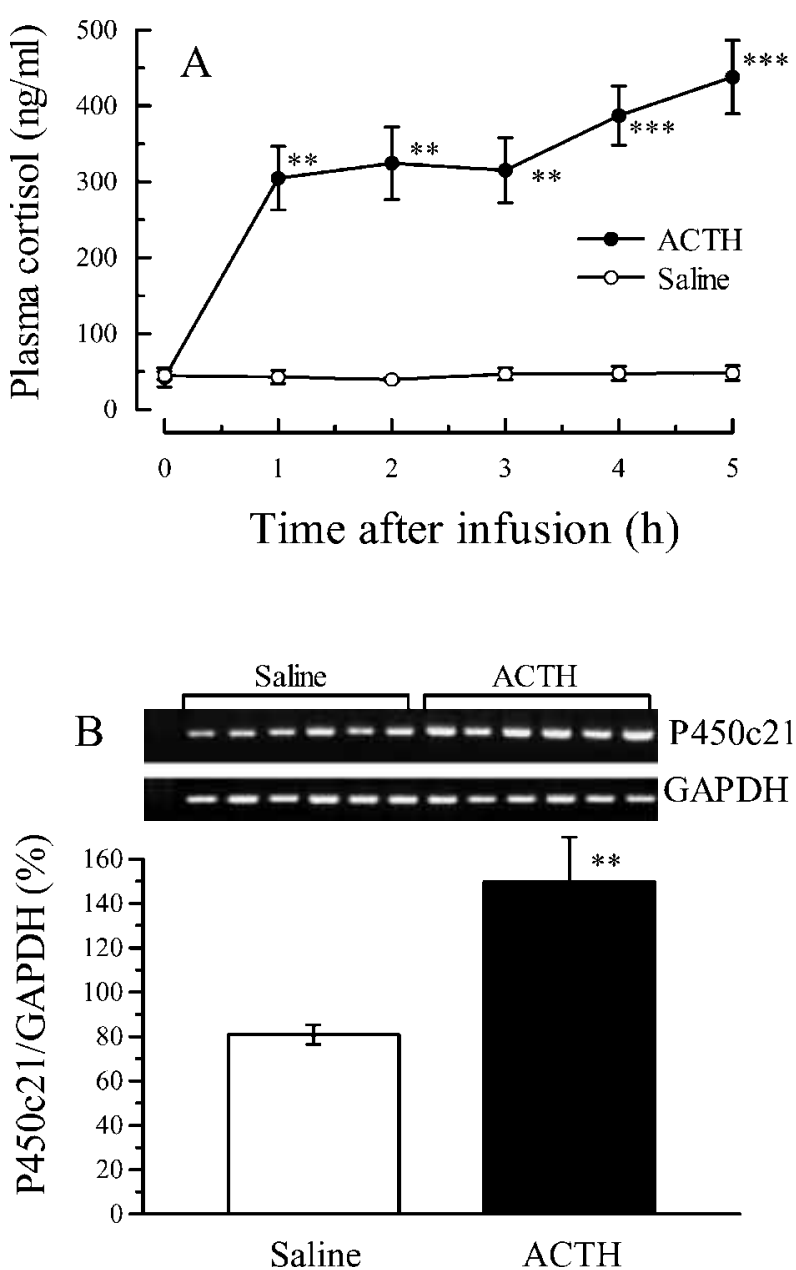

Figure 8 Effects of $A C T H$ infusion on $(A)$ plasma cortisol concentration and (B) P450c21 mRNA levels in the head kidney in SW eels. P450c21 transcripts were quantified by RT-PCR after $5 \mathrm{~h}$ of infusion of ACTH or saline, and were normalized by GAPDH transcripts. Values are means \pm S.E.M. $(n=6) .{ }^{* \star} P<0.01,{ }^{* \star *} P<0.001$ compared with saline-infused controls.

11-deoxycorticosterone is present in fish, although the major route in mammals is thought to be through 17 $\alpha$-hydroxyprogesterone (Hanukoglu 1992). However, since interrenal P450c11 converts 11-deoxycortisol to cortisol (Jiang et al. 1998), there is a possibility that another $\mathrm{P} 450 \mathrm{c} 21$ is also present in the eel interrenal that can 21-hydroxylate $17 \alpha$-hydroxyprogesterone.

\section{Upregulation of P450c21 expression by ACTH}

ACTH is a major stimulator for corticosteroid production in vertebrates. However, the mechanisms of its action are poorly understood in fish. In this study, infusion of ACTH increased both plasma cortisol levels and interrenal expression of the P450c21 gene in eels. This suggests that the increase in plasma cortisol level is mediated, at least in part, by the increased expression of P450c21 gene as already observed in mammals (John et al. 1986, Provencher et al. 1992). In addition, other enzymes responsible for corticosteroid synthesis may also be activated by ACTH as reported in rats (LeHoux et al. 1998). Our recent results have shown that injection of ACTH increased StAR gene expression in the interrenal within $1.5 \mathrm{~h}$ after injection; this was accompanied by an increase in plasma cortisol levels $(\mathrm{Li}$ et al. 2003). Taken together, ACTH may stimulate cortisol production by enhancing the expression of StAR and steroidogenic enzymes including $\mathrm{P} 450 \mathrm{c} 21$ in eels.

\section{Perspectives}

Cortisol is an important hormone for SW adaptation in teleosts (McCormick 2001). Other hormones are also implicated in SW adaptation and some of them, such as ANP, ANG II and urotensin, have been shown to increase cortisol production in eels and other teleost fishes (Henderson et al. 1976, Arnold-Reed \& Balment 1991, 1994, Li \& Takei 2003). To delineate the whole picture of hormonal control of SW adaptation in teleosts, it is necessary to examine how cortisol production is regulated by osmotic adaptation in relation to these peptide hormones. Cloning of eel P450c21 cDNA, together with previously cloned eel P450c11, P450c17 and StAR cDNAs, now allows us to examine how these steroidogenic factors are involved in cortisol production with respect to osmotic adaptation.

\section{Acknowledgements}

We thank Dr Christopher A Loretz of the State University of New York at Buffalo for critical reading of this manuscript, and Dr M K Park of the University of Tokyo for kindly providing COS-1 cells and advice for cell culture. We also thank Dr S Hyodo of the Ocean Research Institute, University of Tokyo, Dr K Ukena of Hiroshima University, Dr T Kobayashi of the National Institute for Basic 
Sciences, and Drs S Adachi, Y Kazeto and K Yamauchi of Hokkaido University for their advice. This work was supported by grants-in-aid for Creative Basic Research (12NP0201) from the Ministry of Education, Culture, Sports, Science and Technology of Japan and for Scientific Research (A) (13304063) from the Japan Society for the Promotion of Science to Y T. Y-Y L is a recipient of a Postdoctoral Fellowship from the Japan Society for the Promotion of Science.

\section{References}

Arnold-Reed DE \& Balment RJ 1991 Atrial natriuretic factor stimulates in vivo and in vitro secretion of cortisol in teleosts. Fournal of Endocrinology 128 R17-R20.

Arnold-Reed DE \& Balment RJ 1994 Peptide hormones influence in vitro interrenal secretion of cortisol in the trout, Oncorhynchus mykiss. General and Comparative Endocrinology 96 85-91.

Blom S, Förlin L \& Andersson TB 2001 Characterisation of head kidney and liver microsomal 17-hydroxyprogesterone 21hydroxylase activity in rainbow trout (Oncorhynchus mykiss) and the lack of regulatory effects of ACTH. Fish Physiology and Biochemistry $241-8$.

Chung BC, Matteson KJ \& Miller WL 1986 Structure of a bovine gene for P450c21 (steroid 21-hydroxylase) defines a novel cytochrome P450 gene family. PNAS 83 4243-4247.

Crawford RJ, Hammond VE, Connell JM \& Coghlan JP 1992 The structure and activity of two cytochrome $\mathrm{P} 450 \mathrm{c} 21$ proteins encoded in the ovine adrenal cortex. Fournal of Biological Chemistry $26716212-16218$.

Dewied D 1990 Neurotrophic effects of ACTH/MSH neuropeptides. Acta Neurobiologiae Experimentalis 50 353-366.

Hanukoglu I 1992 Steroidogenic enzymes: structure, function, and role in regulation of steroid hormone biosynthesis. Fournal of Steroid Biochemistry and Molecular Biology 43 779-804.

Henderson IW, Jotisankasa V, Mosley W \& Oguri M 1976 Endocrine and environmental influences upon plasma cortisol concentrations and plasma renin activity of the eel, Anguilla anguilla L. Fournal of Endocrinology 70 81-95.

Hsu LC, Hu MC, Cheng HC, Lu JC \& Chung BC 1993 The N-terminal hydrophobic domain of P450c21 is required for membrane insertion and enzyme stability. Fournal of Biological Chemistry 268 14682-14686.

Idler DR \& Truscott B 1972 Corticosteroids in fish. In Steroid in Nonmammalian Vertebrates, pp 126-252. Ed DR Idler. New York \& London: Academic Press.

Jiang J, Kobayashi T, Ge W, Kobayashi H, Tanaka M, Okamoto M, Nonaka Y \& Nagahama Y 1996 Fish testicular $11 \beta$-hydroxylase: cDNA cloning and mRNA expression during spermatogenesis. FEBS Letters 397 250-252.

Jiang J, Young G, Kobayashi T \& Nagahama Y 1998 Eel (Anguilla japonica) testis $11 \beta$-hydroxylase gene is expressed in interrenal tissue and its product lacks aldosterone synthesizing activity. Molecular and Cellular Endocrinology 146 207-211.

John ME, Okamura T, Dee A, Adler B, John MC, White PG, Simpson ER \& Waterman MR 1986 Bovine steroid 21-hydroxylase: regulation of biosynthesis. Biochemistry $\mathbf{2 5}$ 2846-2853.

Kahnt FW \& Neher R 1972 On adrenocortical steroid biosynthesis in vitro. Part V. Activators and inhibitors. Evidence for the presence of substrate-specific 21-hydroxylases. Acta Endocrinologica 70 315-330.
Kaiya H \& Takei Y 1996 Atrial and ventricular natriuretic peptide concentrations in plasma of freshwater- and seawater-adapted eels. General and Comparative Endocrinology 102 183-190.

Kazeto Y, Ijiri S, Todo T, Adachi S \& Yamauchi K 2000 Molecular cloning and characterization of Japanese eel ovarian P450c17 (CYP17) cDNA. General and Comparative Endocrinology 118 123-133.

LeHoux JG, Fleury A \& Ducharme L 1998 The acute and chronic effects of adrenocorticotropin on the levels of messenger ribonucleic acid and protein of steroidogenic enzymes in rat adrenal in vivo. Endocrinology 139 3913-3922.

Li Y-Y \& Takei Y 2003 Ambient salinity-dependent effects of homologous natriuretic peptides (ANP, VNP and CNP) on plasma cortisol level in the eel. General and Comparative Endocrinology 130 317-323.

Li Y-Y, Inoue K \& Takei Y 2003 Steroidogenic acute regulatory protein in eels: cDNA cloning and effects of ACTH and seawater transfer on its mRNA expression. Zoological Science $\mathbf{2 0}$ 211-219.

Lofts B \& Bern HA 1972 The functional morphology of steroidogenic tissues. In Steroid in Nonmammalian Vertebrates, pp 108-110. Ed DR Idler. New York and London: Academic Press.

Lorence MC, Trant JM, Mason JI, Bhasker CR, Fujiikuriyama Y, Estabrook RW \& Waterman MR 1989 Expression of a full-length cDNA encoding bovine adrenal cytochrome P450c21. Archives of Biochemistry and Biophysics 273 79-88.

McCormick SD 2001 Endocrine control of osmoregulation in teleost fish. American Zoologist 41 781-794.

Nunez BS \& Trant JM 1995 Characterisation of adrenal cytochrome P450c21 from the blacktip shark (Carcharhinus limbatus). Fournal of Experimental Zoology 272 291-298.

Nunez BS \& Trant JM 1999 Regulation of interrenal gland steroidogenesis in the Atlantic stingray (Dasyatis sabina). Fournal of Experimental Zoology 284 517-525.

Omura T \& Morohashi K 1995 Gene regulation of steroidogenesis. Journal of Steroid Biochemistry and Molecular Biology 53 19-25.

Provencher PH, Tremblay Y, Fiet J \& Belanger A 1992 Effect of ACTH on steroidogenic enzymes in guinea-pig fasciculataglomerulosa cells: changes in activity and mRNA levels. Fournal of Steroid Biochemistry and Molecular Biology 41 59-67.

Sampath-Kumar R, Munro AD \& Lam TJ 1996 Ontogeny of immunoreactive steroidogenic proteins (adrenodoxin and cytochrome $\mathrm{P}-450_{21}$ ) in the interrenals of the teleost Lates calcarifer. General and Comparative Endocrinology 102 147-155.

Sandor T, Vinson GP, Chester Jones I, Henderson IW \& Whitehouse BJ 1966 Biogenesis of corticosteroids in the European eel Anguilla anguilla. Fournal of Endocrinology 34 105-115.

Sangalang GB \& Uthe JF 1994 Corticosteroid activity, in vitro, in interrenal tissue of Atlantic salmon (Salmo salar) parr. 1. Synthetic profiles. General and Comparative Endocrinology 95 273-285.

Stocco DM 2001 StAR protein and the regulation of steroid hormone biosynthesis. Annual Review of Physiology 63 193-213.

Takashima F \& Hibiya T 1995 Interrenal gland and chromaffin cells. In An Atlas of Fish Histology: Normal and Pathological Features, pp 172-174. Eds F Takashima \& T Hibiya. Tokyo: Kodansha Ltd.

Takei Y, Inoue K, Ando K, Ihara T, Katafuchi T, Kashiwagi M \& Hirose S 2001 Enhanced expression and release of C-type natriuretic peptide in freshwater eels. American fournal of Physiology 280 R $1727-\mathrm{R} 1735$.

Tierney ML, Cramb G \& Hazon N 1995 Stimulation of the reninangiotensin system and drinking by papaverine in the seawater eel, Anguilla anguilla. Fournal of Fish Biology 46 721-724.

White PC \& Speiser PW 2000 Congenital adrenal hyperplasia due to 21-hydroxylase deficiency. Endocrine Review 21 245-291.

Yoshioka H, Morohashi K, Sogawa K, Yamane M, Kominami S, Takemori S, Okada Y, Omura T \& Fujii-Kuriyama Y 1986 Structural analysis of cloned cDNA for mRNA of microsomal 
cytochrome P-450(C21) which catalyzes steroid 21-hydroxylation in bovine adrenal cortex. Fournal of Biological Chemistry 261 4106-4109.

Young G 1993 Effects of hypophysectomy on coho salmon interrenal: maintenance of steroidogenic pathway and restoration of in vitro responsiveness to adrenocorticotropin after handling. General and Comparative Endocrinology 92 428-438.
Zhou MY, del Carmen Vila M, Gomez-Sanchez EP \& Gomez-Sanchez CE 1997 Cloning of two alternatively spliced 21-hydroxylase cDNAs from rat adrenal. Fournal of Steroid Biochemistry and Molecular Biology 62 277-286.

Received in final form 3 June 2003 Accepted 3 July 2003 